\title{
An Empirical Study on the Effect of Agricultural Infrastructure Investment on Economic Growth
}

\author{
Liu $\operatorname{ran}^{1, *}$ \\ ${ }^{1}$ Hainan Normal University School of Economics and Management, Hainan, Haikou,571127
}

\begin{abstract}
In this paper, using the panel data of the National Bureau of Statistics database from 2010 to 2019 , and using the random effect model, we studied the impact of agricultural infrastructure investment on economic growth. The empirical results show that the investment in agricultural infrastructure can significantly improve the national economy, among which the investment in new infrastructure promotes the economic growth to a certain extent. After comparing the eastern, central and western regions, it is found that the investment in agricultural infrastructure in the western region contributes more to the economic growth, and the statistical results are more significant. Based on the analysis of the role of agricultural infrastructure investment in promoting economic growth, this paper will further discuss the relevant suggestions of the "two new and one heavy" policy in the agricultural field, and promote the adjustment of agricultural industrial structure with the improvement of agricultural infrastructure, and promote the formation of a new development pattern of "double circulation".
\end{abstract}

\section{Introduction}

Since ancient times, agriculture has been the foundation for human survival and development. On February 21st, 2021, the Central Document No.1 "Opinions of the CPC Central Committee and the State Council on Promoting Rural Revitalization in an All-round Way and Accelerating the Modernization of Agriculture and Rural Areas" was released, which determined that solving the "three rural issues" should be the top priority of the whole party's work during the 14th Five-Year Plan period, and comprehensively promoting rural revitalization should be an important task to realize the great rejuvenation of the Chinese nation. It can be seen that the healthy and stable development of agriculture is vital to the development of national economy. On May 22, 2020, the Government Work Report of the State Council in 2020 put forward to support the construction of "two new and one heavy" (new infrastructure construction, new urbanization construction, transportation, water conservancy and other major projects). Infrastructure is the foundation of industrial development, while agricultural infrastructure is the solid material foundation for the healthy and stable development of agriculture. In 2016, the "No.1 Document" of the Central Committee clearly stated that "promoting the construction of high-standard fields and farmland water conservancy on a large scale, accelerating the construction of production and living infrastructure in rural areas, continuously consolidating the foundation of modern agriculture, and improving the quality, efficiency and competitiveness of agriculture", the construction of agricultural infrastructure has been placed in an important position in agricultural development and rural progress. Therefore, increasing investment in agricultural infrastructure is the best way to promote the endogenous growth of China's rural economy and reasonably solve the problems of agriculture, rural areas and farmers.

Based on the above considerations, this paper uses the panel data of National Bureau of Statistics from 2010 to 2019 to study the impact of agricultural infrastructure investment on economic growth. Compared with the existing literature, the possible innovations of this paper are as follows: 1. Construct a benchmark model and use a fixed effect model to discuss the impact of agricultural infrastructure investment on economic growth from two levels: national panel and regional sub-samples; 2 . Clearly define the concept of agricultural infrastructure, comprehensively consider the research of agricultural infrastructure, including traditional infrastructure construction and new infrastructure construction, and classify the research objects and select variables to analyze the investment of agricultural infrastructure in China.

The structure of the rest of this paper is as follows: the second part introduces the relevant literature on agricultural infrastructure investment at home and abroad, the third part explains the source and pretreatment of this data, the fourth part puts forward the benchmark model, gives the measurement method, possible problems and solutions, the fifth part is the empirical estimation results of the model, the sixth part analyzes the regional regression results according to the heterogeneity test, the seventh part is the endogenous problems and robustness 
test, and the eighth part is based on the previous analysis.

\section{2 literature review}

The relationship between rural infrastructure investment and economic growth has been discussed for a long time, and scholars at home and abroad have done a lot of research on it. The effects of rural infrastructure investment on agricultural production are mainly reflected in agricultural output growth, cost reduction, optimal allocation of agricultural resources and adjustment of agricultural industrial structure, etc. Theoretical literature analyzes the impact mechanism of rural infrastructure investment on agricultural production, and empirical literature provides a lot of empirical evidence for the impact effect of rural infrastructure investment.

\subsection{Foreign research status}

Classical economics usually thinks that capital accumulation is an important factor to promote economic growth. Although the concept of infrastructure has not been put forward at this time, it also lays a theoretical foundation for studying the economic effects of infrastructure capital. Just as Adam Smith (1776), the founder of the classical economics school, pointed out in the article "Research on the Nature and Causes of National Wealth": "Different uses of capital will directly have different impacts on the national industry and the annual output of land and labor. Due to division of labor and specialization, capital accumulation becomes very important"[1].Arrow \& Kurz(1970), the representative of neoclassical economics, introduced the stock of infrastructure capital into the production function model, explored the contribution rate of infrastructure capital to economic output, and started the quantitative study of infrastructure capital ${ }^{[2]}$. Barro(1991), based on the new growth theory, found that infrastructure capital promoted economic growth by improving total factor productivity through capital accumulation effect ${ }^{[3]}$.Most modern literatures take the economic growth theory as the framework, and introduce the variables reflecting infrastructure investment into the production function model, and then estimate the marginal effect of infrastructure on agricultural growth. The research of Bhalla and Singh (2001) shows that investment in irrigation facilities can improve agricultural output, and the promotion of agricultural technology also depends on the improvement of physical infrastructure ${ }^{[4]}$. Thorat and Sirohi (2002) began to focus on the investment in new infrastructure construction, using 10 explanatory variables covering physical infrastructure, finance and research infrastructure: transportation, electricity, irrigation, tractors, research, technology extension institutions, rural credit resources, wholesale markets, convenience of fertilizer sales outlets, and commercial bank outlets to study the effects of infrastructure on agricultural development. Their research found that the investment in new infrastructure construction has the most significant effect on increasing agricultural output $^{[5]}$.Mamatzakis used logarithmic cost function to study the effect of Greek agricultural infrastructure on agricultural economic growth, and found that every one percentage point increase in agricultural infrastructure investment will bring a positive effect of 0.4 percentage points on agricultural productivity ${ }^{[6]}$. Farrow et al. analyzed the rural infrastructure construction in Erdoga, and found that the influence of rural public resources in different regions is different ${ }^{[7]}$.

\subsection{Domestic research status}

Domestic scholars have reached a consensus with foreign scholars on the effect of agricultural infrastructure on economic growth. For example, the research results of Liu Chengfang, Zhang Linxiu and Fan Shenggen (2002) show that the development of rural infrastructure such as communication and transportation can significantly promote farmers' agricultural productive investment ${ }^{[8]}$.Lin Yifu (2003) pointed out that strengthening rural infrastructure construction is an essential prerequisite for rural modernization and can provide new space for the national economic development level ${ }^{[9]}$.Yuan Li's research conclusion shows that in the long run, the increase of infrastructure will improve the efficiency of economic transactions and promote the endogenous growth of rural economy ${ }^{[10]}$. Li Guanyou and other studies believe that "the weak agricultural infrastructure, especially farmland water conservancy facilities, has become the biggest injury affecting the stable development of agriculture and national food security"[11].Zhang Xiusheng and Ma Xiaoming believe that rural infrastructure investment can promote farmers' income growth and expand economic scale ${ }^{[12]}$.Many scholars have analyzed the relationship between agricultural infrastructure and economic development from an empirical perspective. For example, Chen Ling and other empirical methods, such as Granger causality test, believe that there is only one-way causal relationship between rural infrastructure investment and economic growth in China. "We should pay more attention to agricultural infrastructure investment, optimize the investment structure, and promote the benign interaction between rural infrastructure investment and economic growth"[13].Ma Xiaohe and others found that there are still many problems in the current agricultural and rural infrastructure construction by establishing a simultaneous equation model to analyze the relevant data. On this basis, the strategy of agricultural and rural infrastructure construction during the Twelfth Five-Year Plan period was studied ${ }^{[14]}$. Li Zongzhang and others investigated the long-term and short-term effects of rural infrastructure investment on agricultural total factor productivity, and compared the effects of road, irrigation and electricity on agricultural total factor productivity and the differences of action paths $^{[15]}$. 


\section{Indicators and Data Sources}

\subsection{Data source and preprocessing}

This paper uses the provincial panel data of National Bureau of Statistics of China from 2010 to 2019. The statistical scope of this database covers China's national economy and industries, with detailed indicators and comprehensive scope. However, there are some problems in the database of the national data website, such as the lack of observed values in individual areas and the lack of variable statistics. Therefore, it is necessary to preprocess the original data.

In order to ensure the completeness and accuracy of samples, geometric mean method and growth rate prediction method are used to predict and supplement the data, and the data of missing years are supplemented according to the change rate of each province under each index and the trend of data change. After pretreatment, the number of observations is 3720, and the data has strong integrity and representativeness.

\subsection{Selection and construction of main indexes}

1. Economic growth variable (output): choose the regional GDP as the economic growth variable.

2. Core explanatory variables: agricultural infrastructure variables (RI): According to the classification of China's infrastructure construction, infrastructure can be divided into traditional infrastructure and new infrastructure. Traditional rural infrastructure investment has chosen four typical investment types: rural water conservancy facilities investment variables, rural power facilities investment variables, rural transportation investment variables and rural machinery investment variables, while new infrastructure investment has chosen information infrastructure investment variables. Considering the availability of data and the time lag of infrastructure investment effect, this paper:

(1)Investment variables of rural water conservancy facilities (Irrigation): the investment of rural water conservancy facilities mainly refers to the investment used to build irrigation and drainage systems, flood control and drought prevention systems and their maintenance. However, the data published in China Water Resources Yearbook is incomplete, so the effective irrigation area (in thousands of hectares) is selected to measure the investment status of farmland water conservancy in this study.

(2)Investment variables of rural Power facilities (power): With the gradual realization of rural modernization, urban and rural power grid facilities are further improved, and power sources in rural areas are diversified. It is not comprehensive and accurate to measure the investment status of rural power facilities by indicators such as installed capacity of rural hydropower. The rural electricity consumption (unit: 100 million kilowatts) can more intuitively reflect the situation of rural power use.
(3)Rural transportation investment variable (Road): because of the lack of data on rural highway mileage, the national highway mileage (unit: 10,000 kilometers) is used as an alternative indicator of rural transportation investment variable, which indicates that rural roads and urban roads are a whole and inseparable in the process of urban-rural integration.

(4)Investment Mechanism of rural machinery. At present, the mode of agricultural production is changing from extensive to intensive, which is inseparable from the development of agricultural mechanization. The total power of rural machinery (unit: 10,000 kWh) can accurately measure the investment situation of rural machinery.

(5)Information infrastructure investment variable (information) is on the cusp of "new infrastructure", and information infrastructure construction has gradually become the new engine of domestic economic development. Considering the popularization of information infrastructure and the realistic background of Chinese agriculture, the rural broadband access users $(10,000$ households) are selected to reflect the acceptance of farmers in the information age.

3. Control variables: In order to objectively evaluate the impact of rural infrastructure investment on economic growth, the factors that have a significant impact on the study are also selected as control variables in the model. On the basis of referring to the existing literature, this study chooses the following four variables as control variables.

(1)Industry: the proportion of regional industrial GDP to regional GDP. China has a vast territory, and there are great differences in economic development level between regions. The proportion of industrial GDP to regional GDP reflects the industrial structure and regional economic development level of a region.

(2)Natural environment variable (NE): In order to control the impact of agricultural natural disasters on agricultural production, the ratio of affected area to total sown area is introduced to reflect the climatic conditions of agricultural production in various regions.

(3) Local fiscal expenditure on agriculture, forestry and water affairs: Local fiscal expenditure on agriculture, forestry and water affairs is a means to support agricultural development in the form of "redistribution". After 2007, China's statistical caliber on financial support for agriculture has been adjusted to expenditure on agriculture, forestry and water affairs. Here, the proportion of expenditure on agriculture, forestry and water affairs in fiscal expenditure is used as an index to measure expenditure on supporting agriculture.

(4) Crop structure adjustment coefficient (ACPS): Under the background of the new round of agricultural structure adjustment, the main contradiction of agriculture has changed from insufficient total amount to structural contradiction. It is the current key task to promote the adjustment of crop structure, establish the industrial integration mode adapting to the market-oriented mode, and establish the ternary structure of food crops, cash crops and forage crops. In this paper, the proportion of sown area of grain crops to the total 
sown area of all crops is used to express the adjustment of planting structure.

Table 1. Variables and meanings

\begin{tabular}{|c|c|c|}
\hline Variable classification & Variable meaning & $\begin{array}{l}\text { variable } \\
\text { symbol }\end{array}$ \\
\hline $\begin{array}{l}\text { Economic growth } \\
\text { variable }\end{array}$ & $\begin{array}{c}\text { Gross Regional } \\
\text { Product }\end{array}$ & $\mathrm{Y}$ \\
\hline $\begin{array}{c}\text { Investment variables } \\
\text { of rural water } \\
\text { conservancy facilities }\end{array}$ & $\begin{array}{l}\text { Effective irrigation } \\
\text { area }\end{array}$ & $\mathrm{X} 1$ \\
\hline $\begin{array}{c}\text { Investment variables } \\
\text { of rural power } \\
\text { facilities }\end{array}$ & $\begin{array}{l}\text { Rural electricity } \\
\text { consumption }\end{array}$ & $\mathrm{X} 2$ \\
\hline $\begin{array}{l}\text { Rural transportation } \\
\text { investment variables }\end{array}$ & Highway mileage & $\mathrm{X} 3$ \\
\hline $\begin{array}{l}\text { Investment variable of } \\
\text { rural machinery }\end{array}$ & $\begin{array}{c}\text { Total power of rural } \\
\text { machinery }\end{array}$ & $\mathrm{X} 4$ \\
\hline $\begin{array}{l}\text { Investment variables } \\
\text { of information } \\
\text { infrastructure }\end{array}$ & $\begin{array}{c}\text { Rural broadband } \\
\text { access users }\end{array}$ & $\mathrm{X} 5$ \\
\hline Industrial structure & $\begin{array}{c}\text { Industrial added } \\
\text { value/regional GDP }\end{array}$ & X6 \\
\hline $\begin{array}{c}\text { Natural environment } \\
\text { variable }\end{array}$ & Disaster rate & $\mathrm{X} 7$ \\
\hline $\begin{array}{c}\text { Financial expenditure } \\
\text { variables for } \\
\text { supporting agriculture }\end{array}$ & $\begin{array}{l}\text { Expenditure on } \\
\text { agriculture, forestry } \\
\text { and water affairs }\end{array}$ & $\mathrm{X} 8$ \\
\hline $\begin{array}{l}\text { Adjustment coefficient } \\
\text { of planting structure }\end{array}$ & $\begin{array}{c}\text { Seeded area of } \\
\text { grain crops/total } \\
\text { sown area of crops }\end{array}$ & X9 \\
\hline
\end{tabular}

\section{Empirical results and analysis}

\subsection{Benchmark model}

Based on the above analysis, the model is set as follows:

$$
Y_{\mathrm{it}}=\beta_{0}+\beta_{1} X_{\mathrm{tt}}+\beta_{2} X_{2 t}+\beta_{3} X_{3 t}+\beta_{4} X_{4 t}+\beta_{5} X_{5 t}+\alpha \text { Control }_{i t}+\varepsilon_{i t}
$$

Among, Said the regional GDP, $X_{1 \mathrm{t}}$ Indicates the effective irrigated area, $X_{2 \mathrm{t}}$ Represents rural electricity consumption, $X_{3 \mathrm{t}}$ Indicates road mileage, $X_{4 \mathrm{t}}$ Represents the total power of rural machinery, $X_{5 \mathrm{t}}$ Represents rural broadband access users, Control it is a control variable, Mainly include: industrial structure, disaster rate, local finance expenditure on agriculture, forestry and water affairs, adjustment coefficient of planting structure. $\varepsilon_{\mathrm{it}}$ represents the random perturbation term of the model.

\subsection{Estimation method}

In the selection of fixed effect, random effect and mixed regression model, the following considerations are made in this paper. First of all, in the choice of panel regression and mixed regression, this paper does F-test on the original hypothesis of mixed OLS. The results show that Prob $>F=0.0000$ rejects the original hypothesis at the significance level of 0.01 , so it is more reasonable to use panel regression. Secondly, the results of Hausman test on the model show that the value of Hausman test is less than the critical value of significance level $(5 \%)$, and we cannot reject the zero hypothesis. Therefore, the random effect model should be selected as the benchmark model for estimation.

\subsection{Possible Problems and Solutions of the Model}

(1) Multicollinearity problem

In order to test whether there is multicollinearity among various variables, the variance expansion factor (VIF) of the model is calculated. The results show that the average variance expansion factor of the model is 3.11, and the maximum variance expansion factor of all variables is 5.40 , which is less than the empirical value of 10 . Based on this, this paper considers that there is no obvious multicollinearity problem in the model.

Table 2. Variance Expansion Factors for Each Variable

\begin{tabular}{ccc}
\hline Variable & VIF & $1 /$ VIF \\
\hline x8 & 5.40 & 0.185156 \\
x1 & 4.35 & 0.230148 \\
x4 & 4.19 & 0.238534 \\
x3 & 3.87 & 0.258262 \\
x5 & 3.85 & 0.260017 \\
x2 & 2.25 & 0.445126 \\
x6 & 1.65 & 0.607143 \\
x9 & 1.29 & 0.777267 \\
x7 & 1.14 & 0.876716 \\
Mean VIF & 3.11 &
\end{tabular}

(2) Endogenous problem

This paper studies the impact of agricultural infrastructure investment on economic growth. The endogenous problem of the model mainly tests whether the variables are related to the error term, which comes from missing variables and reverse causality. For the problem of missing variables, this paper adds the important control variables that may affect the problem at the national macro level, such as industrial structure, disaster rate, local finance expenditure on agriculture, forestry and water affairs, adjustment coefficient of planting structure, etc. For the reverse cause-and-effect problem, the endogenous cause is that regional economic growth has a positive impact on the construction of agricultural infrastructure. In the sixth part, we use instrumental variable method to test endogenous problems.

(3) Robustness problem

In the sixth part, the robustness is tested by eliminating the total samples and using sub-sample regression. 


\section{Results of Empirical Analysis}

With regard to economic growth, this paper is concerned about the influence of rural water conservancy facilities investment variables, rural power facilities investment variables, rural transportation investment variables, rural machinery investment variables and information infrastructure investment variables on economic growth. Each variable is regressed by random effect model, and the results are reported in Table 3. Among them, the (1) column is the result of regression with only core variables such as rural water conservancy facilities investment variables, rural power facilities investment variables, rural transportation investment variables, rural machinery investment variables and information infrastructure investment variables, and the (2) column is the regression result after considering all the above core variables and control variables.

Table 3. Regression results of benchmark model and regression results of eastern, central and western regions based on panel data

\begin{tabular}{|c|c|c|c|c|c|}
\hline & (1) & (2) & (eastern) & (midland) & (western) \\
\hline & $\mathrm{y}$ & $\mathrm{y}$ & $\mathrm{y}$ & $\mathrm{y}$ & $\mathrm{y}$ \\
\hline \multirow[t]{2}{*}{$\mathrm{x} 1$} & $-2.337^{* * *}$ & $-2.772^{* * *}$ & $-7.098^{* *}$ & $-1.966^{* * *}$ & $-0.754^{* *}$ \\
\hline & $(-2.90)$ & $(-3.37)$ & $(-2.18)$ & $(-4.31)$ & $(-2.16)$ \\
\hline \multirow[t]{2}{*}{$\mathrm{x} 2$} & $26.73^{* * *}$ & $25.41^{* * *}$ & $19.66^{* * *}$ & -5.010 & $36.79^{* *}$ \\
\hline & (13.56) & (12.80) & $(5.48)$ & $(-0.41)$ & $(2.42)$ \\
\hline \multirow[t]{2}{*}{$\mathrm{x} 3$} & $32.28^{* * *}$ & $29.78^{* * *}$ & 350.9 & $1250.9^{* * *}$ & $245.0^{* * *}$ \\
\hline & (19.66) & (14.68) & $(0.55)$ & $(8.00)$ & (2.69) \\
\hline \multirow[t]{2}{*}{$\mathrm{x} 4$} & $688.1^{* * *}$ & $458.2^{* * *}$ & $2.582^{* * *}$ & $0.551^{*}$ & $1.191^{* *}$ \\
\hline & $(4.68)$ & $(2.84)$ & $(3.48)$ & (1.69) & $(2.47)$ \\
\hline \multirow[t]{2}{*}{$\mathrm{x} 5$} & $1.006^{* * *}$ & $0.889^{* *}$ & $34.02^{* * *}$ & $19.34^{* * *}$ & $20.86^{* * *}$ \\
\hline & $(2.81)$ & $(2.52)$ & $(8.62)$ & $(5.83)$ & $(8.54)$ \\
\hline \multirow[t]{2}{*}{$\mathrm{x} 6$} & & $20281.8^{* * *}$ & $27420.7^{*}$ & $19373.5^{* *}$ & $15699.8^{* * *}$ \\
\hline & & (3.68) & (1.90) & $(2.13)$ & (4.29) \\
\hline \multirow[t]{2}{*}{$\mathrm{x} 7$} & & -1706.3 & -787.0 & $-10454.3^{* * *}$ & $-7025.8^{* * *}$ \\
\hline & & $(-0.83)$ & $(-0.20)$ & $(-3.20)$ & $(-3.22)$ \\
\hline \multirow[t]{2}{*}{$\mathrm{x} 8$} & & $10.08^{* * *}$ & $22.63^{* * *}$ & $15.24^{* * *}$ & $3.843^{*}$ \\
\hline & & (3.89) & $(3.53)$ & (4.14) & $(1.79)$ \\
\hline \multirow[t]{2}{*}{ x9 } & & 8966.2 & 7273.5 & $10466.2^{* *}$ & $7823.2^{* * *}$ \\
\hline & & $(1.52)$ & $(0.51)$ & $(2.36)$ & $(2.63)$ \\
\hline \multirow[t]{2}{*}{ _cons } & -707.1 & $-13019.1^{* * *}$ & -13950.8 & $-23432.9^{* * *}$ & $-8967.7^{* * *}$ \\
\hline & $(-0.35)$ & $(-2.69)$ & $(-1.14)$ & $(-3.15)$ & $(-3.89)$ \\
\hline$N$ & 310 & 310 & 110 & 80 & 120 \\
\hline
\end{tabular}

\section{Analysis of regional regression results (heterogeneity test)}

The 31 provinces, municipalities and autonomous regions in Chinese mainland are divided into the east, the middle and the west according to the Document No.33 of National Development and Reform Commission in 2000. The eastern region includes 11 provinces and cities including Beijing, Tianjin, Hebei, Liaoning, Shanghai, Jiangsu, Zhejiang, Fujian, Shandong, Guangdong and Hainan; The central region includes 8 provinces and cities including Shanxi, Jilin, Heilongjiang, Anhui, Jiangxi, Henan, Hubei, Hunan and Chongqing; The western region includes 10 provinces and cities such as Sichuan, Guizhou, Yunnan, Shaanxi, Gansu, Qinghai, Ningxia, Xinjiang, Guangxi, Inner Mongolia and Tibet Autonomous Region, and then uses random effect 
templates to explore the heterogeneity of the impact of agricultural infrastructure investment on economic growth in the three regions. As shown in Table 3, for the regression results, compared with the eastern, central and western regions, the statistical results in the western region are more significant, and the impact of agricultural infrastructure investment on economic growth is more obvious. Comparing the five core explanatory variables, "rural broadband access users" (X5) has a significant impact on the economic growth of the three regions.

\section{Endogenous and robust test}

\subsection{Endogenous problem}

This paper controls endogeneity in two ways. One is to use control variables, such as industrial structure, disaster rate, local financial expenditure on agriculture, forestry and water affairs, and adjustment coefficient of planting structure, etc. On the other hand, this paper uses the panel data from 2010 to 2019 of the industrial and enterprise database, and uses the random effect model to regress. However, these two approaches can only solve the endogeneity at the level of missing variables, and neither the covariant nor the random effect model can solve the endogeneity from the perspective of reverse causality. Therefore, this paper considers using the tool variable method to solve the endogeneity problem. According to Sun Churen's (2015) method, this paper uses the explanatory variable of the first-stage lag as the tool variable for endogeneity test. This is because: on the one hand, the index of agricultural infrastructure investment in the first-stage lag is highly correlated with the current index; on the other hand, the only way for the index of the first-stage lag to affect economic growth is through the current agricultural infrastructure investment index. Therefore, the index of the first-stage lag satisfies the relativity and exclusiveness, which is a reasonable tool variable.

Table 4. Endogenous problems

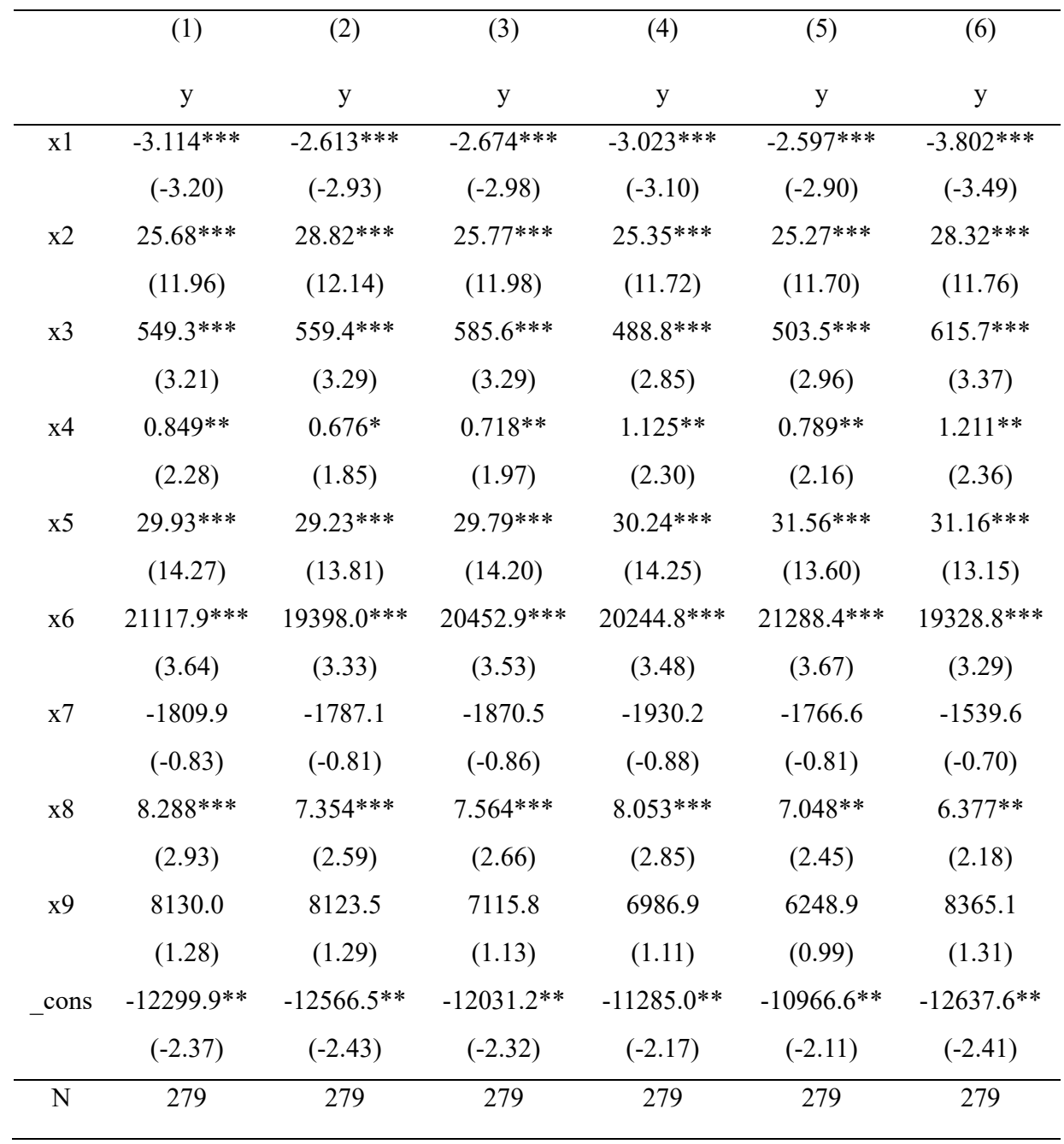

Columns (1) to (5) of the output result are the estimation results using the lag periods of five core explanatory variables as tool variables respectively, and column (6) is the regression result using three tool variables synthetically.Comparing the results of instrumental variable regression and benchmark regression, we can find that the estimators are basically consistent with the significance, Therefore, in this paper, 
from the perspective of adding covariates, the endogenous problems caused by missing variables are well controlled.

\subsection{Robustness test}

Considering the regional heterogeneity of the impact of agricultural infrastructure investment on economic growth, This paper examines the robustness of regression results from the perspective of sub-samples, The sample is divided into three regions: eastern, central and western, and then all the data of the corresponding provinces in the three regions are deleted to test the robustness of the sample. The deleted ones are Tianjin, Shanxi and Tibet Autonomous Region. As shown in Table 5:

Table 5. Robustness Test

\begin{tabular}{|c|c|c|c|c|}
\hline & (1) & (2) & (3) & (4) \\
\hline & $\mathrm{y}$ & $\mathrm{y}$ & $\mathrm{y}$ & $\mathrm{y}$ \\
\hline \multirow[t]{2}{*}{$\mathrm{x} 1$} & $-2.772^{* * *}$ & $-2.446^{* * *}$ & $-2.568^{* * *}$ & $-2.534^{* * *}$ \\
\hline & $(-3.37)$ & $(-2.96)$ & $(-2.99)$ & $(-2.86)$ \\
\hline \multirow[t]{2}{*}{$\mathrm{x} 2$} & $25.41^{* * *}$ & $25.37^{* * *}$ & $25.29^{* * *}$ & $25.23^{* * *}$ \\
\hline & (12.80) & (12.80) & (12.51) & (12.25) \\
\hline \multirow[t]{2}{*}{$\mathrm{x} 3$} & $458.2^{* * *}$ & $505.0^{* * *}$ & $501.7^{* * *}$ & $525.1^{* * *}$ \\
\hline & $(2.84)$ & (3.09) & $(3.00)$ & (3.06) \\
\hline \multirow[t]{2}{*}{$\mathrm{x} 4$} & $0.889^{* *}$ & $0.850^{* *}$ & $0.876^{* *}$ & $0.857^{* *}$ \\
\hline & $(2.52)$ & $(2.41)$ & $(2.36)$ & $(2.27)$ \\
\hline \multirow[t]{2}{*}{$\mathrm{x} 5$} & $29.78^{* * *}$ & $30.13^{* * *}$ & $30.23^{* * *}$ & $30.06^{* * *}$ \\
\hline & (14.68) & (14.72) & (14.45) & (14.08) \\
\hline \multirow[t]{2}{*}{ x6 } & $20281.8^{* * *}$ & $21826.0^{* * *}$ & $23366.5^{* * *}$ & $25464.1^{* * *}$ \\
\hline & $(3.68)$ & $(3.81)$ & $(3.85)$ & (3.90) \\
\hline \multirow[t]{2}{*}{$x 7$} & -1706.3 & -1240.4 & -1079.2 & -997.9 \\
\hline & $(-0.83)$ & $(-0.59)$ & $(-0.50)$ & $(-0.45)$ \\
\hline \multirow[t]{2}{*}{$\mathrm{x} 8$} & $10.08^{* * *}$ & $9.533^{* * *}$ & $9.893^{* * *}$ & $10.49^{* * *}$ \\
\hline & (3.89) & $(3.63)$ & $(3.62)$ & $(3.73)$ \\
\hline \multirow[t]{2}{*}{$\mathrm{x} 9$} & 8966.2 & 3968.6 & 4603.1 & 2608.8 \\
\hline & $(1.52)$ & $(0.65)$ & $(0.71)$ & $(0.38)$ \\
\hline \multirow[t]{2}{*}{ _cons } & $-13019.1^{* * *}$ & $-11693.0^{* *}$ & $-12543.3^{* *}$ & $-12717.5^{* *}$ \\
\hline & $(-2.69)$ & $(-2.42)$ & $(-2.49)$ & $(-2.45)$ \\
\hline$N$ & 310 & 300 & 290 & 280 \\
\hline
\end{tabular}

(1) of the output results is the random effect estimation result of the original data, and (2) to (4) columns are the estimation results obtained by removing the data of the eastern, central and western representative provinces respectively. Compared with the benchmark regression, the regression results have certain robustness.

\section{Conclusion and policy suggestions}

Infrastructure is an important support for economic and social development. Facing the requirement of high-quality economic development, it is the key to coordinate the development of traditional and new infrastructure. Different from the existing research literature, this paper studies the impact of agricultural infrastructure investment on economic growth, and further explores the regional dynamics of agricultural infrastructure development and economic growth. The main conclusions of this paper are as follows:

(1)The coefficient of investment variable of farmland water conservancy facilities is negative, which shows that the improvement of farmland irrigation conditions has not promoted economic growth. However, according to historical experience and literature research, the increase of investment in farmland water conservancy facilities can improve irrigation conditions and agricultural production capacity in rural areas. However, with the development of today's science and technology, the extensive growth mode relying on land and labor has lost its original charm, and the investment cycle of farmland water conservancy is longer and the profit is lower. Moreover, the improvement of cultivated land conditions can't be achieved overnight, and its contribution to economic growth can't be seen quickly. On the other hand, it shows that to achieve economic growth in agriculture, we should rely more on scientific and technological innovation, and rely on today's information science and technology to provide effective development space for economic growth.

(2) Investment in rural power facilities, rural transportation, rural machinery and information infrastructure are all positively correlated with economic growth. When rural power supply, transportation, machinery and communication conditions are improved, it will bring positive economic effects; Among them, the impact of information infrastructure investment on economic growth is significant, and its contribution rate to economic growth is relatively high, whether in different regions or at the national level.

(3) In the eastern, central and western provinces, investment in agricultural infrastructure is significant to economic growth on the whole. Compared with the three regions, the statistical results in the western region are more significant, and the impact of investment in agricultural infrastructure on economic growth is more obvious. The western region is rich in mineral resources, energy, tourism, land and other resources. The region relies more on primary industries such as agriculture, but the improvement of agricultural infrastructure contributes more to economic growth, while the eastern region has the advantages of capital and talents, with most industries.

Table 6. Basic conclusions of empirical research

\begin{tabular}{|c|c|c|c|c|}
\hline $\begin{array}{c}\text { Irrigation } \\
\text { and water } \\
\text { conservan } \\
\text { cy } \\
\text { Facility }\end{array}$ & $\begin{array}{c}\text { Rural } \\
\text { electric } \\
\text { power } \\
\text { Facility } \\
\text { investm }\end{array}$ & $\begin{array}{c}\text { Rural } \\
\text { traffic } \\
\text { investm } \\
\text { ent }\end{array}$ & $\begin{array}{c}\text { Rural } \\
\text { machine } \\
\text { ry } \\
\text { investm } \\
\text { ent }\end{array}$ & $\begin{array}{l}\text { Informati } \\
\text { on } \\
\text { foundatio } \\
\text { n Facility } \\
\text { investme }\end{array}$ \\
\hline
\end{tabular}




\begin{tabular}{|c|c|c|c|c|c|}
\hline & $\begin{array}{c}\text { investme } \\
\text { nt }\end{array}$ & ent & & & nt \\
\hline $\begin{array}{c}\text { Econo } \\
\text { mic } \\
\text { growth }\end{array}$ & $(-)$ & $(+)$ & $(+)$ & $(+)$ & $(+)$ \\
\hline
\end{tabular}

Based on the above empirical analysis results, we can promote investment in agricultural infrastructure and achieve high-quality economic growth from the following aspects:

(1) Increase investment in agricultural infrastructure and innovate investment methods and investment subjects

In the aspect of investment in agricultural infrastructure, the traditional practice of state finance is changed. Because of the long construction period and payback period of agricultural infrastructure and weak profitability, many financial institutions show the characteristics of "reluctant to lend", resulting in few sources of funds and insufficient credit funds. In order to solve this problem, the government should first increase the proportion of financial funds for supporting agriculture, give appropriate agricultural subsidies for agricultural infrastructure construction, and provide financial sources for agricultural infrastructure construction. Secondly, we should make full use of market mechanism and preferential policies to attract all kinds of investors, establish an investment and financing platform for agricultural infrastructure based on market mechanism, guide private capital to participate, and diversify investors. And refer to innovative financing modes such as BOT, ABS or PPP to provide financial guarantee for improving the supply of agricultural infrastructure.

(2) To strengthen the agricultural water conservancy, electricity, machinery, agricultural products market information and other production infrastructure investment or procurement subsidies

At present, most of China's agricultural labor force is concentrated in planting. Therefore, strengthening investment or purchasing subsidies for productive infrastructure such as water conservancy, electricity, machinery and the provision of agricultural product market information can greatly reduce the risks of farmers engaging in animal husbandry, fishery and forestry. The government should focus on building a perfect service system for agricultural products, helping farmers to master the market information and sales channels of agricultural products, speeding up the adjustment of the internal industrial structure of agriculture, and developing agriculture towards high efficiency and high added value. First of all, we should carry out the construction and transformation of rural power grid, deepen the reform of rural power system, improve the stability of power supply, promote the intensive production of agricultural modernization, bring about the innovation of agricultural production mode, and then improve the total factor productivity of agriculture; Secondly, although the research shows that investment in water conservancy facilities does not effectively promote economic growth, special funds should still be used to make overall arrangements and improve the construction of water conservancy facilities, so as to promote their development after a long period of time. In addition, in terms of rural roads, attention should also be paid to the construction and management of rural roads in the long run, and overall planning must be made, road network layout should be optimized, and traffic accessibility in rural areas should be improved to inject vitality into the growth of rural economy.

(3) Strengthen inter-provincial cooperation and realize the transformation of agricultural economic structure

According to the viewpoint of Boarnet \& Haughout [16]: "Appropriate infrastructure investment in underdeveloped areas can bring higher marginal returns", in order to strengthen infrastructure investment in the western region and improve the total factor productivity of agriculture in the region, human capital should play a significant role in promoting the region, give full consideration to the geospatial effect, strengthen cooperation and progress between provinces, continuously strengthen the spatial overflow of positive effects of rural infrastructure, realize the free flow of people, capital and products in the east, central and western regions, realize the optimal allocation of social resources, reduce the impact of natural environmental disasters, and improve the quality and efficiency of agricultural products supply.

\section{References}

1. Smith, A. An Enquiry into the Nature and Causes of the Wealth of Nations, Glasgow Edition of the Works and Correspondence of Adam Smith, 2 vols[J]. Glasgow: Glasgow Publishers. 1976

2. Arrow, K. J. \& Kurz, M. Public investment, the rate of return, and optimal fiscal policy[J]. BALTIMORE, THE JOHNS HOPKINS PRESS, 1970. 218 P. 1970

3. Barro, R. J. Economic growth in a cross section of countries $[\mathrm{J}]$. The quarterly journal of economics. 1991,106 (2): 407-443

4. Bhalla, G. S. and Singh, G. 2001. Indian agriculture: Four decades of development [M]. Sage Publications, New Delhi

5. Thorat, S. and S., S. 2002. Rural infrastructure: State of indian farmers, a millennium study, [R]. Ministry of Agriculture, Government of India, New Delhi

6. MAMATZAKIS E C. Public infrastructure and productivitygrowth in Greek agriculture [J] . Agriculture Economics，2003， 29 (2) : 169 -180 .

7. FARROW A, LARREA C, HYMANANDL G. Exploring the spatial variation of food poverty in ecuador [J]. Food Policy, 2005, 30 ( 5) : 510531 .

8. Liu Chengfang, Zhang Linxiu, Fan 
Shenggen.2002.Study on the Influencing Factors of Farmers' Agricultural Productive Investment-An Empirical Analysis of Six Counties and Cities in Jiangsu Province [J]. china rural survey, (4):20-28.

9. Lin Yifu. "Three Rural Issues" and the Future Development of Rural Areas in China [J]. Agricultural Economic Issues, 2003 (1): 19-24.

10. Yuan Li. Analysis of the Effect of Infrastructure Investment on Rural Economic Growth [J]. Journal of Sichuan Administration College, 2006 (3): 88-90.

11. Zhang Hongyu, Li Guanyou, Yang Jiemei. Key areas and policy ideas for accelerating agricultural infrastructure construction. Rural Economy, 2011( 6): 6- 8.

12. Zhang Xiusheng, Ma Xiaoming. Analysis of the Interaction between Rural Social Security and Farmers' Income Growth [J]. Journal of Wuhan University (Philosophy and Social Sciences Edition), 2009 (2): 255-260.

13. Chen Ling, He Yanan. Research on the Relationship between Agricultural Infrastructure Investment and Economic Growth in China [J]. Journal of Fujian Business School, 2017,(02):1-8.

14. Ma Xiaohe, Zhenzhong Liu. Study on the Strategy of Agricultural and Rural Infrastructure Construction during the Twelfth Five-Year Plan Period [J]. Agricultural Economic Problems, 2011,32(07):4-9+110.

15. Li Zongzhang. Study on the Impact of Rural Infrastructure Investment on Agricultural Total Factor Productivity [D]. Tutor: Li Ding 'an. South China University of Technology, 2013.

16. Boarnet, M. G. \& Haughwout, A. F. Do Highways Matter? Evidence and Policy Implications of Highways' Influence on Metropolitan Development[J]. 2000. 